\title{
¿Para qué sirve la gramática tensiva?*
}

\author{
Claude Zilberberg \\ (Centro Nacional de Investigación Científica de París, CNRS)
}

Recibido: 22/11/08

Aprobado: 19/01/09

Resumen: A la pregunta provocativa ¿Para qué sirve la gramática tensiva?, Claude Zilberberg responde con una reflexión que resume sus teorías sobre la tensividad y su función en la producción de sentido. Después de una puntualización sobre la "lengua y el sentido", plantea los problemas mismos de la gramática tensiva, comenzando por la construcción de las categorías que le son propias: la intensidad y la extensidad, fundamentalmente, como valencias que definen y determinan los valores; el intervalo que regula los problemas de la cantidad; la sintaxis de la intensidad y sintaxis de la extensidad; para terminar con la problemática del valor, que es el que está siempre en el punto de mira.

Palabras clave: Gramática tensiva - lengua y sentido - categorías tensivas intervalo - sintaxis intensiva - sintaxis extensiva - utilidad - aplicaciones.

\section{¿What is tense grammar for?}

SUMMARY: The interesting question ¿What does tense grammar is for?, is answered by Claude Zilberberg with a reflection that captures its theories about tensivity and its function in the production of sense. After a clarification on "language and sense", he raises the issues of tense grammar, starting with the construction of its own categories: intensity and extensity, mainly, as valences that define and determinate there own values; the interval that regulates the quantity problems; the syntax of intensity and syntax of extensity; to finish with the value problematic, which is always in the sight.

Key words: Tense grammar - language and sense - tense categories - interval intensive syntax - extensive syntax - usefulness - applications.

* Traducción. Desiderio Blanco. 
Le mystère est que, dans le moment même où le langage est ainsi obsedé de lui-même, il lui est donné, comme par surcroît, de nous ouvrir à une signification. *

M. Merleau-Ponty

$\mathrm{E}$ 1 título provocador: ¿para qué sirve la gramática tensiva? no nos pertenece. Proviene de los brasileños L. Tatit, I. Lopes y W. Beividas. Desde el punto de vista subjetal, la locución interrogativa: ¿para qué sirve? corresponde a la configuración del desafío, la cual, según Greimas, ${ }^{1}$ pone en duda la competencia del enunciatario para ejecutar el programa propuesto. Una de dos: o el enunciatario no responde al desafío, y, en ese caso, queda descalificado; o acepta el desafío y su realización es actualizada, es decir, anticipada como insuficiente por el enunciador [de la pregunta]:

En el caso de la provocación por desafío, que es la que nos interesa en este momento, el mensaje persuasivo del sujeto manipulador que acompaña la proposición de contrato consiste en significar al sujeto que uno se prepara a manipular su falta de competencia: el sujeto S2 es así invitado a ejecutar cierto programa (PN) y al mismo tiempo queda advertido de su insufi- ciencia modal (del "no poder hacer") para efectuarlo. $^{2}$

Desde el punto de vista objetal, la locución: ¿para que sirve? deja entrever un fondo de escepticismo en el caso más favorable, si es que no de nihilismo, dando a entender que las construcciones conceptuales son, como los seres de la naturaleza, perecibles, y que basta, en suma, con tener paciencia, y que los libros perduran, con esfuerzos y cuidados considerables, como plano de la expresión, pero no, ciertamente, como plano del contenido. La locución ¿para qué sirve?, si el enunciatario la recibe, se convierte en una invitación al heroísmo, o al ridículo si es que no logra el objetivo que se ha fijado: convencer a su contendor en potencia.

El programa propuesto comporta una segunda demanda no modalizada: el lenguaje y el sentido. Ambas demandas son muy diferentes. La primera: el lenguaje y el sentido, es una invitación a evaluar el grado de comunicación que se puede establecer entre dos magnitudes que presentan, ya un aire de familia, una relación de similaridad según Jakobson, ya una vecin-

* "El misterio reside en que, cuando el lenguaje se ve obsesionado por sí mismo, adquiere, como por añadidura, la capacidad de abrirnos a una significación".

1 GREIMAS, A. J. “El desafío". Del sentido II, 1989, pp. 242-254. Como hace con frecuencia, Greimas toma por punto de partida, por germen, la definición del diccionario: el desafío es "una declaración provocadora por medio de la cual uno le hace saber a alguien que lo considera incapaz de hacer una cosa".

2 Ibídem, p. 244. 
dad, una relación de contigüidad, siempre según Jakobson. La segunda demanda: ¿para qué sirve la gramática tensiva? conlleva una dimensión personal en la medida en que yo he podido contribuir al desarrollo del punto de vista tensivo; en ese sentido, apela a la dimensión argumentativa e intersubjetiva del discurso, puesto que nos enfrentamos siempre a entimemas, es decir, según Aristóteles, a silogismos truncos. Comenzaremos por la primera demanda: el lenguaje y el sentido.

\section{La lengua y el sentido}

Una observación preliminar se impone: consideraremos aquí las relaciones entre la lengua y el sentido. El término de lenguaje tiene dos acepciones: una acepción elevada, cuando designa una facultad superior, y actualmente, una acepción corriente, cuando designa la presencia de un código sumario, como por ejemplo el semáforo que regula la circulación de los vehículos. Lo mismo se puede decir de otras tantas señales que algunos seres animados intercambian entre sí, como por ejemplo el lenguaje de las abejas descifrado por Von Frisch, aunque la distancia con el lenguaje humano es tan considerable que el término parece francamente abusivo. La problemática relativa a la facultad del lenguaje pertenece indudablemente a la antropología y las cuestiones que trata son de temer. Desde el punto de vista diacrónico, la aparición del lenguaje desafía el pensamiento. Por su parte, Lévi-Strauss estima que el lenguaje, tal como se revela, "no ha podido nacer más que de golpe": ${ }^{4}$ en efecto, una creación progresiva reposa en una petición de principio, puesto que el sujeto, en ese caso, ¡debería actualizar lo que ignora! Pero una creación espontánea tampoco es pensable. Desde el punto de vista sincrónico, el problema más arduo reside en la tipología de las lenguas, y está muy lejos de haber sido resuelto. Por lo demás, lenguas no estudiadas desapare-

3 En el capítulo "Tipología de las estructuras lingüísticas" de la obra titulada El lenguaje, Hjelmslev precisa, a partir de su teoría de las relaciones, las principales articulaciones a las que recurren las lenguas (1968).

4 "Cualesquiera que hayan sido el momento y las circunstancias de su aparición en la escala de la vida animal, el lenguaje no ha podido nacer más que de un solo golpe. Las cosas no han podido ponerse a significar progresivamente. Como consecuencia de una transformación, cuyo estudio no corresponde a las ciencias sociales, sino a la biología y a la psicología, se produjo un salto de un estadio en el que nada tenía sentido, a otro en el que todo lo tenía. Ahora bien, esta observación, en apariencia banal, es importante, porque ese cambio radical no tiene contrapartida en el dominio del conocimiento, el cual se elabora lenta y progresivamente" ("Introducción a la obra de M. Mauss", en MAUSS, M. Sociología y antropología, 1979. [p. XLVII de la edición francesa, París: Minuit, 1960]). 
cen sin que siquiera tengamos noticia de ellas, de suerte que la búsqueda tipológica, aunque tuviera éxito, sería siempre incompleta.

Con estas precauciones, la palabra más misteriosa, la más embarazosa también es, sin duda, la conjunción " $y$ " en la medida en que proyecta entre los términos que enlaza una simetría, una igualdad, un contraste o al menos una conmensurabilidad: el día y la noche, el bien y el mal, lo duro y lo blando, para Bachelard... La conjunción de coordinación " $y$ " constituye una suerte de "caja de herramientas" mental en la cual rebuscamos. En esa "caja" encontramos principalmente el "porque" y el "por tanto"; el "porque", que inyecta causalidad en el discurso; el "por tanto", que apela a la racionalidad. Con esto consolidamos la " $y$ " de nuestra redacción, pues la lengua proporciona al sujeto hablante útiles preciosos que le preceden y sobreviven.

La " $y$ " interesa al plano de la expresión y proporciona una escena a la relación que conviene establecer entre el sentido y la lengua. A partir del inventario de las relaciones estructurales establecidas por Hjelmslev en los Prolegómenos, ${ }^{5}$ se presentan dos posibilidades: 1) la indiferencia y la coincidencia, que recibe el nombre de "constelación"; 2) la interdependencia y la dependencia unilateral, que denominamos "determinación". La respuesta depende, en parte, de la concepción de la lengua que uno adopte. Si uno tiene una concepción bastante laxa de la lengua, el sentido se organiza según sus vías y sus tensiones propias, y la lengua no es más que un vehículo. Después de todo, la narratividad canónica derivada de los análisis de Propp no debe a la lengua el sentido que manifiesta, lo mismo que las características de una melodía agradable son ajenas al soporte sobre el cual están grabadas.

A W. Humboldt se debe, sin duda, una de las primeras formulaciones de la tesis que plantea la dependencia del sentido de la lengua que lo enuncia: "Lo que distingue las lenguas entre sí no son tanto los sonidos y los signos, sino las visiones del mundo que organizan". En eso residen, según Humboldt, el fundamento y la meta última de toda investigación sobre el lenguaje. ${ }^{6}$ Sin embargo, la postulación de la noción de visión del mundo no tiene el mismo sitio que el que nosotros estamos dispuestos a atribuirle. Para nosotros, es el sujeto; de ahí, por ejemplo, la derivación, en el plano de la expresión, de un adjetivo a partir de un nombre propio respetado, como

5 HJELMSLEV, L. Prolegómenos a una teoría del lenguaje, 1971, p. 42.

6 CASSIRER, E. Filosofía de las formas simbólicas, tomo 1, 1998, p. 112. 
"Balzac" que da por extensión "balzaciano", o "Mozart", "mozartiano"...

Cada lengua es portadora de una subjetividad compartida, y la convocación de las lenguas funda una objetividad para Humboldt: "La subjetividad del conjunto de la humanidad se convierte en algo objetivo".

La expresión "visión del mundo" puede prestarse a un malentendido en la medida en que parece tomar en cuenta la percepción visual para reconocer el estado de los lugares. La metáfora a la que recurre Humboldt es musical: "Si los hombres se comprenden, $[\ldots]$ es porque tocan la misma cuerda de su instrumento espiritual, lo cual desencadena en cada uno de los interlocutores conceptos que se corresponden entre sí sin ser exactamente los mismos". 8

En el mismo espíritu, significar consiste en hacer, así como la música no comienza hasta que el ejecutante hace sonar su instrumento; de ahí la formula: "[...] el lenguaje no es una obra (ergon) sino una actividad (enérgeia)". ${ }^{9}$ Este punto de vista es retomado por Hjelmslev en los Principios de gramática general: "Lo sincrónico es una actividad, una enérgeia". ${ }^{10}$ Así, en presencia de la bifurcación intrigante entre morfología y sintaxis, la significación como propuesta de sentido está más bien del lado de la frase.

Hjelmslev mantiene categóricamente la tesis de la dependencia unilateral del sentido en relación con la lengua: "La lengua es la forma por medio de la cual concebimos el mundo. No existe teoría del conocimiento, objetiva y definitiva, sin recurso a los hechos de lengua. No hay filosofía sin lingüística". ${ }^{11}$

En los Prolegómenos, Hjelmslev propone dos ejemplos de la dependencia estrecha que existe entre la epistemología y la lingüística. En primer lugar, identifica la "deducción" y el análisis:

El único procedimiento posible para descubrir el sistema que sostiene un texto es un análisis que considere el texto como una clase analizable en componentes; esos componentes serán, a su vez, considerados como clases analizables en otros componentes; y así sucesivamente, hasta agotar las posibilidades de análisis. [...] La lingüística contemporánea [...] ha designado este procedimiento [...] con el término de deducción. ${ }^{12}$

7 Ibídem.

8 Ibídem, p. 114.

9 Ibídem.

10 HJELMSLEV, L. Principes de grammaire générale, 1928, p. 56.

11 HJELMSLEV, L. “Essai d'une théorie des morphèmes". Essais linguistiques, 1971, p. 173.

12 HJELMSLEV, L. Prolegómenos a una teoría del lenguaje, 1971, pp. 25-26. 
Luego, en el capítulo diez, identifica el "análisis-deducción" con la "conclusión lógica":

Nuestras definiciones en nada contradicen o impiden el empleo de la palabra deducción en el sentido de "conclusión lógica". Creemos que es posible decir que proposiciones que se deducen de otras proposiciones resultan así por análisis: en cada nivel del procedimiento, las proposiciones deducidas son objetos que dependen unos de otros de manera homogénea, así como dependen todos de la proposición presupuesta. ${ }^{13}$

El segundo ejemplo se refiere a la relación que engarza entre sí el sincretismo y la implicación. En principio, un sincretismo, o también la neutralización, "consiste en el hecho de que, con ciertas condiciones, la conmutación entre dos invariantes puede ser suspendida" ${ }^{14}$ El concepto de implicación es introducido en los siguiente términos:

$\mathrm{Si}$, en una lengua, las consonantes sordas y sonoras establecen una conmutación mutua, y si, delante de otra consonante, esa conmutación es suspendida, de tal suerte que una sorda se trasforma en sonora delante de otra sonora, hay implicación. ${ }^{15}$
La dinámica de la relación se establece así: "[...] en determinadas condiciones, una consonante sorda implica una consonante sonora, y una consonante sonora es implicada por una consonante sorda" ${ }^{16}$ La asunción de la implicación lógica por la implicación lingüística es prácticamente obvia para Hjelmslev:

Se puede observar que el empleo que hacemos del término implicación concuerda exactamente con el que hace la lógica y no es más que una aplicación particular del mismo. La implicación es una función "si...entonces" que, en nuestros ejemplos se aplica no a proposiciones, sino a magnitudes de menor extensión: si tenemos la magnitud de expresión glosemática $p$ en una relación dada con alguna otra, entonces tendremos $q$. La implicación lógica entre proposiciones constituye otro caso particular de la implicación lingüística. ${ }^{17}$

A partir de estos dos casos, la lengua obliga al pensamiento.

La actitud de la semiótica greimasiana a propósito de la implicación traduce cierto embarazo en la medida en que reduce la implicación a la presuposición: la proposición introducida por "si" es planteada como presupo-

13 Ibídem, p. 52.

14 Ibídem, p. 125.

15 Ibídem, p. 128.

16 Ibídem, p. 129.

17 Ibídem. 
niente, la proposición que introduce "entonces", como presupuesta; la presuponiente implica la presupuesta. Por otra parte, la implicación interviene en el funcionamiento del cuadrado semiótico, puesto que es ella la que se encarga de los pasajes de [no $S_{1}$ ] a $\left[S_{2}\right]$ y de $\left[\right.$ no $S_{2}$ ] a $\left[S_{1}\right]$, pero esa transitividad ha sido puesta en duda en nombre de la gradualidad y de la complejidad. Como señalaba B. Pottier, el "no-rico" no es forzosamente "pobre": solamente lo es con una condición que el cuadrado semiótico ignora.

A modo de ilustración, se puede citar la tesis de F. Mauthner, quien considera que la tabla de las categorías establecida por Aristóteles no hace más que calcar las categorías de la gramática griega, lo cual significa que nadie estaría en capacidad de pensar mas allá o fuera de la lengua que utiliza. Dentro del mismo espíritu, son muchos los que subrayan la relación tan estrecha que tiene la filosofía de Heidegger con la lengua alemana, y, en menor medida, con la lengua griega. ${ }^{18}$ En efecto, para Heidegger, pensar consiste en desenmarañar el juego de prefijos y sufijos de una palabra cualquiera. La misma preocupación encontraremos en W. Benjamin: “La convicción que me guía en mis tentativas literarias [...] [es] que toda verdad tiene su mansión, su residencia ancestral en la lengua...". ${ }^{19}$ Pero esa disposición no se limita a los pensadores y a los creadores si atendemos a Cassirer: "En ese sentido, palabras que pertenecen a lenguas diferentes jamás pueden ser sinónimas". ${ }^{20} \mathrm{De}$ esa dependencia de las significaciones en relación con la lengua y la cultura que son las nuestras aportaremos otro ejemplo. En una de las sesiones del seminario que dirigía, Greimas advirtió la reacción de un suizo a la lectura de su estudio sobre la cólera, ${ }^{21}$ el suizo le hizo una objeción embarazosa: que su estudio analizaba la cólera francesa, es decir, una cólera específica, tributaria de la lengua y de la cul-

18 Según G. Steiner: "Y ya en Ser y Tiempo, Heidegger acude a la etimología. La palabra simple, aceptada desde siempre, servirá precisamente para que encierre, según él, la mayor carga de una percepción inicial y válida. Y así, las palabras antiguas y claras son las más ricas de sentido. Lo que pasa es que nosotros hemos olvidado su fuerza fundamentalmente incisiva y su testimonio existencial. Por medio de una meditación antigua, acompañada de una suerte de vehemente esfuerzo de penetración, acerca de la etimología y de la historia primitiva de una palabra, el pensador puede obligarla a liberar su formidable quantum de iluminación y de energía" (Martin Heidegger, 1981, p. 20).

19 ARENDT, H. Walter Benjamin 1892-1940, 2007, p. 102.

20 CASSIRER, E. Op. cit., p. 267.

21 GREIMAS, A. J. “De la cólera, estudio de semántica lexical”. Del sentido II. Op. cit., pp. 255-280. 
tura francesa. Nosotros añadiríamos por nuestra cuenta que en Michaux se encuentran varios textos referentes a la cólera, que se alejan de la perspectiva greimasiana.

Es difícil apreciar el alcance de la tesis sostenida por Hjelmslev. Si nos atenemos solamente a la retórica argumentativa, es muy fuerte, puesto que afecta a dos operaciones mayores e incesantes: la deducción y la implicación; pero esa fuerza es también su límite. Nos gustaría mostrar, a propósito de un ejemplo, también limitado, que entre la lengua y la práctica se constata un isomorfismo, sin que podamos, no obstante, zanjar la cuestión de la anterioridad. El estudio diacrónico muestra que la expresión del tiempo y la expresión del aspecto, es decir, de los modos de actuar, son desiguales; que la expresión de los modos de la acción es más rica que la del tiempo, con frecuencia demasiado sumaria y más tardía. De esa riqueza, Cassirer da una idea en las líneas siguientes:

Distinguimos la acción que comienza ‘bruscamente' de la acción que se desarrolla poco a poco, la que se cumple de un salto de aquella que se desarrolla en continuidad, la que constituye un todo único de la que puede descomponerse en fases idénticas que se repiten con cierto ritmo. ${ }^{22}$
Además, repetitivas, las acciones de los hombres tienen su tempo, su tono, su ritmo, su cifra, en una palabra, su prosodia inmanente que condiciona su eficiencia inmediata y que aprecia el cuerpo agente, y su transmisibilidad. En la primera frase, Cassirer toma en cuenta eso que nosotros hemos llamado modo de eficiencia, es decir, la alternancia entre el "sobrevenir" como principio del evento y el "llegar a" como principio del ejercicio. Pero, ¿dónde está la residencia primera o última del evento? ¿En la lengua o en la vivencia? El evento está "en" la lengua si se conviene en hacer de la exclamación el pivote sincrético de la estructura frástica, pero está igualmente "en" la retórica tropológica, según Fontanier, y soporta una figura raramente mencionada, la abrupción:

El nombre de Abrupción le conviene mejor que cualquier otro, sin duda, a la figura que aquí tenemos en vista. Este nombre expresa bastante bien, si no me equivoco, lo que puede entenderse por pasaje brusco, imprevisto, por pasaje "ex abrupto". Se trata precisamente de designar una figura por la cual se suprimen las transiciones usuales entre las partes de un diálogo, o delante de un discurso directo, a fin de hacer la exposición más animada y más interesante. ${ }^{23}$

22 CASSIRER, E. Op. cit., p. 191.

23 FONTANIER, P. Les figures du discours, 1968, p. 342. 
Si Fontanier hace del evento una figura, H. Focillon lo acepta como una categoría estética, o sea, como una magnitud metalingüística: “QQué es el evento? Acabamos de decirlo: una 'brusquedad' eficaz". ${ }^{24} \mathrm{El}$ evento está, pues, "en" el sentido y "en" la lengua: en el sentido, en virtud de las valencias extremas de tempo y de tonicidad que manifiesta, y en la lengua, en razón de la forma exclamativa o interjectiva que selecciona:

Se dice en particular que la expresión "manitu" es empleada siempre que la representación y la imaginación son excitadas por algo nuevo y extraordinario: si, durante la pesca, uno atrapa una especie aún desconocida de peces, eso hace surgir de inmediato la expresión de "manitu" [...]. Las expresiones de "wakan" y de "wakan$\mathrm{da}^{\prime \prime}$, entre los Sioux, parece que remontan etimológicamente a interjecciones que traducen el asombro. ${ }^{25}$

Registramos una correspondencia, una concordancia entre el sentido y la lengua de acuerdo con la condición indicada al comienzo por Humboldt: los contenidos "se corresponden sin ser exactamente los mismos".

\section{¿Para qué sirve la gramática tensiva?}

Quisiéramos, primero, llamar la atención sobre la economía singular de la teoría en las llamadas ciencias humanas. Anticipando un poco, consideramos que la sintaxis tensiva comporta dos vertientes: una sintaxis intensiva que procede por aumentos y por disminuciones, y una sintaxis extensiva que procede por selecciones y por mezclas, las cuales no tienen nada de peyorativo, puesto que presuponen, respectivamente, análisis y síntesis. Existen dos vías para que una teoría se desarrolle: una aproximación axiomática que propone principios, de hecho definiciones, a partir de los cuales deduce consecuencias que, por inversión, se convierten en presuponientes. Este acercamiento es el que se practica en Semiótica 1, especialmente en las entradas "densas" como "cuadrado semiótico" y "recorrido generati$v o^{\prime \prime}$. Un segundo acercamiento, totalmente diferente, consiste en mezclarlos, a partir de "deudas" y de préstamos declarados. Eso es lo que nosotros hemos tratado de hacer en el estudio consagrado a la obra de Greimas en Raison et poétique du sens. ${ }^{26}$ Allí distinguíamos seis "herencias": la herencia

24 FOCILLON, H. Vie des formes, 1996, p. 99.

25 CASSIRER, E. Op. cit., tomo 2, p. 110, n. 7.

26 ZILBERBERG, Cl. "Greimas et le paradigme sémiotique". Raison et poétique du sens, 1988, pp. 65-94. 
ginebrina (Saussure), la herencia praguense (Jakobson), la herencia danesa (Bröndal y Hjelmslev), la herencia rusa (Propp), la herencia francesa (Tesnière), la herencia alemana (Husserl, Merleau-Ponty).

Considerada en esa perspectiva, una teoría puede ser evaluada de acuerdo con tres criterios: el número, el acento y la pulidez. El número de los préstamos puede ser reducido o amplio. Por ejemplo, Hjelmslev no reconoce más que un solo predecesor: Saussure. ${ }^{27}$ Por acento, entendemos la selección del préstamo decisivo, aquel que le da a la teoría su orientación; si comparamos Semántica estructural y Semiótica 1, esta última debe su orientación a la adopción de la epistemología austera desarrollada en los Prolegómenos y no a la que se presenta en La categoría de los casos. Finalmente, la pulidez designa, para un observador atento, la calidad de homogeneidad obtenida, puesto que una mezcla es lograda si las trazas de las magnitudes en préstamo han sido borradas, virtualizadas. Si ninguna teoría consistente, o lo que es lo mismo, recibida, puede evitar esa dependencia respecto de aquellas que la han precedido, es porque las teorías, como los productos del bricolaje en su orden, aparecen como puntos de vista, lo que de ninguna manera las descalifica.
Bajo estas premisas, las teorías presentan cierta analogía con los juegos de cartas. De un juego a otro, las mismas cartas, afectadas de valores diferentes (Saussure), son regidas por reglas sintácticas diferentes. Cada juego tiene sus reglas particulares, su sintaxis, a veces sumaria, porque depende ampliamente del azar, a veces sutil, que exige grandes competencias y una práctica continua. En El pensamiento salvaje, Lévi-Strauss ha propuesto otra metáfora, la del bricolaje: del bricoler, Lévi-Strauss escribe que

[...] su universo instrumental está cerrado, y la regla de su juego consiste siempre en arreglarse con los "medios que tiene a mano" es decir, con un conjunto a cada instante finito de instrumentos y de materiales, heteróclitos a lo sumo, ya que la composición del conjunto no está en relación con el proyecto del momento ni, por lo demás, con ningún proyecto particular, sino que es el resultado contingente de todas las ocasiones que se han presentado de renovar el stock o de conservarlo en buen estado con los residuos de construcciones o de destrucciones anteriores. ${ }^{28}$

El análisis del bricolaje apela a la indulgencia. Otra metáfora apareció después, la del reciclaje. ¿La consecuencia? Se enuncia así: si todas las

27 Para Hjelmslev, “Un solo teórico merece ser citado como antecesor indiscutible: el suizo Ferdinand de Saussure" (Prolegómenos a una teoría del lenguaje, 1984, p. 17).

28 LÉVI-STRAUSS, Cl. El pensamiento salvaje, 1984, pp. 35-36. 
teorías están combinadas, mezcladas, juzgar una teoría es juzgar una pluralidad, una diversidad de hecho. En esas condiciones, el rechazo de una teoría en ciencias humanas no es cosa fácil. Si volvemos a la teoría greimasiana, esperamos haber mostrado que dicha teoría incorpora adquisiciones apreciables y para algunos sin duda definitivas. ${ }^{29}$ Como indica Vendryes, la negación no siempre logra su objetivo.

Tenemos que decir algunas palabras sobre la forma misma de la teoría. Dicha forma depende del objeto que uno elige. Si nos remitimos, como personalmente lo hacemos con frecuencia, a las obras ejemplares de Wölfflin, llegamos a dos observaciones simples: en primer lugar, un microuniverso responde a un estilo, según la acepción que le da MerleauPonty en La prosa del mundo: "Un estilo es lo que hace posible toda su significación". ${ }^{30}$ En segundo lugar, un estilo está emparejado con otro en diacronía o en sincronía. En materia de estilo, la unidad es dos, la unidad es una dualidad. En otras palabras, solo la comparación es ilustrativa. La cosa se complica un poco si se considera que, para Wölfflin, el arte del Renacimiento se coloca más bien del lado del "llegar a" y el arte barroco más bien del lado del "sobrevenir". De todos modos, esa distribución no es fortuita: en el microuniverso prosaico de Baudelaire, tal como emerge de eso que se llama los "diarios": $F u$ sées y Mon coeur mis à $n u$, dos vías le parecen posibles al poeta, la del trabajo asiduo, solidario del "llegar a", y la del juego solidario del "sobrevenir". En su Tratado de lo sublime, Longino opone Demóstenes a Cicerón en los siguientes términos: "En efecto, Demóstenes es grande por lo que tiene de cerrado y de conciso; Cicerón, por el contrario, lo es por lo difuso y extendido". ${ }^{31}$ Demóstenes y Cicerón se oponen en función de los lugares respectivos que ocupan en el espacio tensivo, y podríamos multiplicar los casos. De este examen rápido surgen dos puntos de reflexión: (i) la forma de la teoría es tributaria de las categorías que elige como directrices; (ii) por análisis o catálisis, dichas categorías, una vez analizadas o completadas, responden a categorías tensivas, en este caso a las que agrupamos en el modo de eficiencia, es decir, a la alternancia existencial entre el "sobrevenir" y el "llegar a".

Es preciso decir ahora unas palabras sobre la forma de la hipótesis ten-

29 Según Hjelmslev, “En el dominio científico, se puede muy bien hablar de resultados definitivos, pero apenas de puntos de vista definitivos" (El lenguaje, 1968, p. 27).

30 MERLEAU-PONTY, M. La prose du monde, 1999, p. 81.

31 Longino. Traité du Sublime, 1995, p. 93. 
siva. La teoria greimasiana, tal como aparece en Semiótica 1, es una teoría estratificada y dual. El "recorrido generativo" que la resume comprende tres niveles, y cada nivel es a su vez doble, puesto que incluye una dimensión semántica y una dimensión sintáctica. En el caso de la semiótica tensiva, el objeto está constituido por una pareja, de tal modo que la forma de la teoría es dual. Tiene por plano de la expresión esa pareja, y por plano del contenido una complejidad constituida por un par de magnitudes: la intensidad y la extensidad, valencias definicionales que están correlacionadas entre sí. Es también dual porque, en concordancia con la esquicia de la tensividad en intensidad y extensidad, desdobla la semántica en semántica intensiva y semántica extensiva, y procede del mismo modo con la sintaxis, en la medida en que distingue igualmente una sintaxis intensiva $\mathrm{y}$ una sintaxis extensiva. Evidentemente, se produce una cierta circularidad, puesto que la teoría se forja a imagen del objeto que se da a sí misma, pero nosotros creemos que esa circularidad es virtuosa. En función de las características señaladas: el punto de vista y la forma, las teorías se presentan como variaciones a partir de un fondo de invariantes, que representa, por un tiempo que hay que precisar, la episteme válida.

\section{Las categorías}

Que una teoría proponga categorías es lo menos que se puede pedir. Sin embargo, el término de "categoría" se ha hecho tan corriente que recubre diferencias notables de interpretación. Las categorías semióticas y lingüísticas, comparadas con las categorías filosóficas o conceptuales, presentan una particularidad: los términos que constituyen la categoría ocupan un lugar en la cadena. Esa exigencia explica la centralidad de la conmutación, que permite fijar el efectivo de la categoría: "la prueba de conmutación es pertinente para el análisis del contenido lingüístico". ${ }^{32}$ Esa adhesión al "orden de las posiciones" en el proceso distingue la categoría semiótica de la categoría filosófica. Ese mismo empeño constituye el mérito implícito y definitivo del trabajo de Propp.

Las magnitudes no están simplemente yuxtapuestas unas a otras, sino coordinadas o subordinadas entre sí: constituyen una estructura como principio de la definición de los valores. Para una teoría que propone los conceptos asociados de jerarquía y de dependencia, los primeros pasos son decisivos. Hemos tomado de Hjelmslev la pareja [extenso vs intenso], invirtiendo sus aportes. Esta pareja [extenso vs intenso] se sitúa en el umbral de la deducción de las categorías. Para el

32 HJELMSLEV, L. Prolegómenos a una teoría del lenguaje. Op. cit., p. 107. 
autor de los Prolegómenos, esa oposición se refiere a la presencia/ausencia de una propiedad sintáctica: la dirección. Los exponentes extensos, o mejor verbales [del verbo] ostentan dicha propiedad, los exponentes intensos, o mejor nominales, carecen de dirección. El polo marcado es, por tanto, el de lo extenso. A nuestra escala, nosotros oponemos la intensidad, como suma de los estados de alma, a la extensidad, como suma de los estados de cosas; esta partición responde al reparto entre la propioceptividad y la exteroceptividad. La marca recae ahora sobre la intensidad, que se propone como regente de la extensidad [a la que consideramos como regida]. Esa desigualdad no es la única: aceptamos la intensidad en calidad de manifestada y la extensidad como manifestante.

Creemos que este recurso a la manifestación permite resolver una dificultad perenne, a saber, la relación que existe entre las categorías lingüísticas y las categorías semióticas. La deuda que tiene la semiótica con la lingüística es considerable, pero no es nuestro propósito ocuparnos ahora de ese aspecto. Queremos solamente iluminar la zona en la que la lingüística y la semiótica entran en contacto la una con la otra hasta el punto de confundirse. Lo haremos a partir de un pasaje de La poética del espacio, de Bachelard, consagrado a la /redondez/ del pájaro, en la cual Michelet ve una figura de la /concentración/: ${ }^{33}$

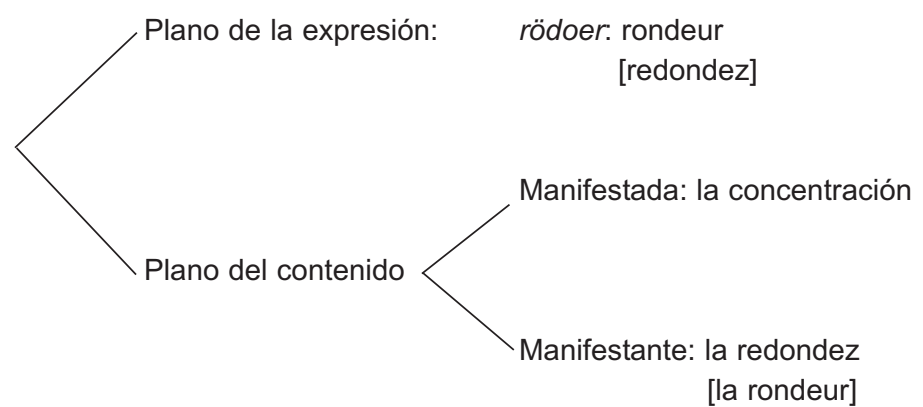

33 Michelet escribe: "El pájaro, casi esférico, es ciertamente la cúspide, sublime y divina, de la concentración viviente. No se puede ver ni imaginar siquiera un más alto grado de unidad", citado por G. Bachelard en Poética del espacio, 1997, p. 276. Véase ZILBERBERG, Cl. "Portrait de la rondeur", en PAROUTY-DAVID, Fr. y Cl. ZILBERBERG. Sémiotique et esthétique, 2003, pp. 99-112. 
Este esquema muestra el encaje de las dos funciones: (i) la función semiótica, que deriva en este caso del análisis lingüístico, reúne el significante /rõdoer/ con el significado/rondeur/ [redondez]; (ii) la función simbólica, que procede del análisis semiótico, acepta la /redondez/ como una manifestante de la /concentración/ en calidad de manisfestada. Esta última función es interna al plano del contenido y proporciona al metalenguaje, ocasional o sistemático, su base. Desde el punto de vista discursivo, la función simbólica es una respuesta a la pregunta directa: ¿pero cuál es la significación discursiva de la /redondez/? La /redondez/ es, para Michelet y Bachelard, la /concentración/. Lo esencial, sin embargo, está tal vez en otra parte: si se admite que la manisfestada es ideal, nocional o incluso conceptual..., vemos que la función simbólica dota a la manifestada, en concordancia con la hipótesis del esquematismo en Kant, de una imagen, o mejor aún de un icono. Varias observaciones se imponen en este punto: las magnitudes del contenido reconocidas como lexicales no son todas del mismo orden; las manifestantes pueden ser asimiladas a los semas figurativos, mientras que las manifestadas, magnitudes fugurales, dependen de las valencias y de las subvalencias; la diferencia remite a una desigualdad fuerte en la epistemología hjelmsleviana, a saber, que lo que hace sentido es la desigualdad y la dinámica de los inventarios: los inventarios ilimitados se retiran ante los inventarios limitados. Y de hecho, los semas son en número si no ilimitado, al menos considerable, mientras que las valencias y las subvalencias son $-\mathrm{y}$ tocamos aquí el corazón mismo del proceder hipotético, cualquiera que sea- en número restringido. Si interrogamos ahora a la manifestada, podremos constatar que es ella la que le permite a Hjelmslev articular una oposición mayor en La categoría de los casos, pero ausente en los Prolegómenos: la oposición entre el término intensivo y el término extensivo: "La casilla que se escoge como intensiva tiene tendencia a concentrar la significación, mientras que las casillas elegidas como extensivas tienden a expandir la significación sobre las otras casillas, de tal modo que llegan a invadir el dominio semántico ocupado por la zona". 34 De suerte que el tratamiento de una cuestión semántica se reduce a observar la densidad semántica de las magnitudes puestas en discurso: ¿tal maguitud es incompartida y exclusiva?, ¿o bien difusa, compartida, indefinidamente distribuida?

El concurso "poiético" de la dimensión de la intensidad y de la

34 HJELMSLEV, L. La categoría de los casos, 1978, p. 155. Nuestra posición a propósito de la deuda personal que tenemos con la terminología hjelmsleviana se puede formular así: asumimos la pareja [intensivo vs extensivo], pero no asumimos la pareja [intenso vs extenso]. 
dimensión de la extensidad puede, si intervienen ciertas convenciones sencillas, ser representado gráficamente: (i) por una convención de definición contrastiva: la dimensión de la intensidad tiene como funtivos lo /fuerte/ y lo /débil/; la dimensión de la extensidad tiene como funtivos lo /concentrado/ y lo /difuso/; (ii) una convención de composición asociativa, cuya dinámica la hemos tomado de G. Deleuze, a saber, que si no se toma ninguna precaución,

[... ]la intensidad se explica, se desarrolla en una extensión (extensio). Dicha extensión la transporta a la amplitud (extensum), donde aparece fuera de sí, recubierta por la calidad. La diferencia de intensidad se anula o tiende a anularse en ese sistema; pero es ella la que crea ese sistema explicándose. ${ }^{35}$

Podemos organizar así un espacio tensivo colocando la intensidad en la ordenada y la extensidad en la abscisa; dicho espacio queda definido, como lo recomienda Hjelmslev, por una doble "intersección":36 la intersección de lo /fuerte/ con lo /concentrado/ produce lo /estallante/ [o lo /brillante/], la intersección de lo /débil/ con lo /difuso/ produce lo /distribuido/, [o lo /opaco/], que es, en principio, simétrico e inverso de lo /estallante/, aunque los diccionarios no proponen antónimo satisfactorio de /estallante/. Eso nos da el siguiente esquema:

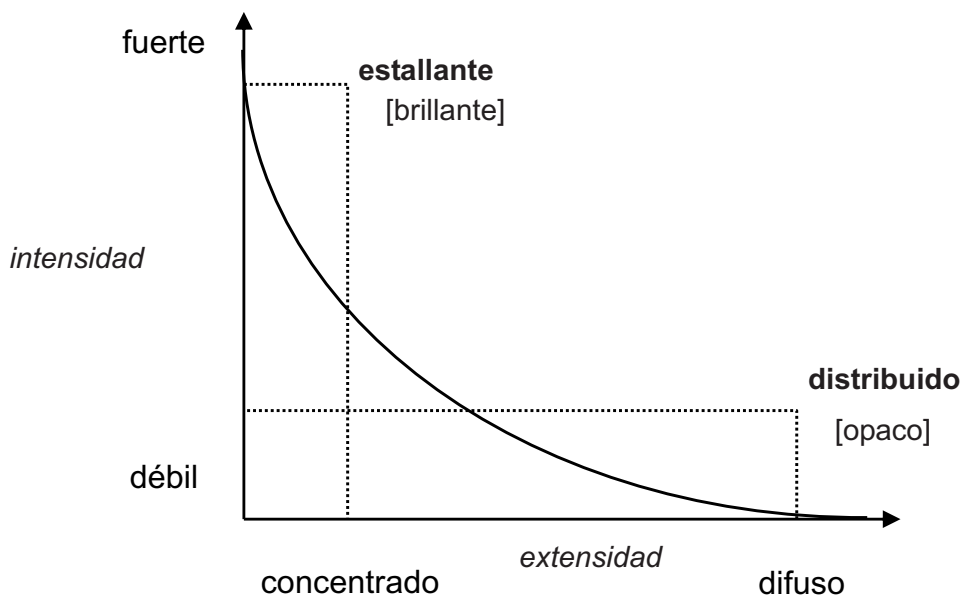

35 DELEUZE, G. Différence et répétition, 1989, p. 294.

36 “Los 'objetos' del realismo ingenuo se reducen, pues, a puntos de intersección de esos haces de relaciones" (Prolegómenos a una teoría del lenguaje). Op. cit., pp. 40-41. 
Desde el punto de vista terminológico, lo /estallante/ y lo /distribuido/ son valores. Un valor semiótico es definido por la "intersección" de una valencia intensiva y de una valencia extensiva. Desde el punto de vista espistemológico, una definición recae sobre una complejidad, y como lo enseña Hjemslev: "Eso nos lleva a la definición de la definición: por definición entendemos una división sea del contenido de un signo, sea de la expresión de un signo". ${ }^{37}$

Un sistema como dispositivo, como espacio conmutativo, reúne para el sujeto coerciones y latitudes. El sistema propone ante todo una alternancia, un "o bien... o bien", en este caso, de orden axiológico. La coerción cifrada, por tanto hipotética, estipula que el producto de las valencias para cada uno de los casos, lo /estallante/ y lo /distribuido/ obedezca a un principio de constancia que, con "los medios de que disponemos", podríamos transcribir así:

Fuerte $x$ concentrado $\approx$ débil $x$ difuso $\approx \mathbf{k}$

Lo que equivale a decir, después de una inversión, que la intensidad funciona como un dividendo, la extensi- dad como un divisor, y el valor como un cociente que tiende a la estabilidad. Con esto tocamos dos problemáticas conexas: (i) el tratamiento de ciertas estructuras postula innegablemente la subyacencia de una cantidad no numérica, distinta de aquella tratada por la comparación de grados: ¿cómo pensar, sin esa demanda insólita, la simultaneidad decadente de la intensidad y la expansión de la extensión que acoge esta intensidad dispersándola?; (ii) ese principio de constancia sería uno de los componentes de la identidad personal o colectiva. Para poner un ejemplo fácil, que resulta, ciertamente, un lugar común, pero que, precisamente por eso tiene un valor indudable, ¿el tempo del citadino no pasa por ser más rápido que el tempo del campesino? Observador atento de la interoceptividad, Michaux anota:

Cada cual trata, sin que nadie se lo haya indicado, de mantener su tempo. En todos los niveles: en los acontecimientos, en las emociones, en las aventuras, así como requiere mantener igual su temperatura lo mismo en estaciones frías que en lugares tórridos.

Por medio de un balance sabio y constante, entre las incitaciones que uno acepta y aquellas otras que deja de lado, por medio de un equilibrio com-

37 Ibídem, p. 104. 
plejo, donde las pequeñas ralentizaciones y las pequeñas aceleraciones se encuentran ingeniosamente compensadas. $^{38}$

Bajo estas premisas, la complejidad, la definición analizante y la división se convierten en puntos de vista recíprocos.

\section{De la cantidad al intervalo}

Hemos hablado de una cantidad no numérica, fórmula que por el momento participa del oxímoron. La cantidad está por todas partes, y tal vez por eso le resulta fácil disimularse. Se encuentra en el corazón del elogio, es decir, del género epidíctico, si vamos a creer a Baudelaire cuando hace el elogio caluroso de actor [comediante] Philibert Rouvière:

[Las obras meditadas] contienen la gracia literaria suprema, que es la energía. Ocurre lo mismo con Rouvière: tiene esa gracia suprema, decisiva - la energía, la intensidad en el gesto, en el habla y en la mirada. ${ }^{39}$
De acuerdo con el uso, una gramática comprende una morfología, es decir, una semántica, y una sintaxis, es decir, una lista probablemente finita de operaciones simples. ${ }^{40}$ Para la semiótica greimasiana, la morfología es proporcionada por las estructuras elementales de la significación, y a partir de Semiótica 1, por el cuadrado semiótico. Dos reproches se le han hecho a esa asignación: (i) las estructuras elementales desconocen, de hecho si no de derecho, la cantidad y la gradualidad; sin duda, las dos operaciones de contradicción: [S1 $\rightarrow$ no S1] y [S2 $\rightarrow$ no S2] eran planteadas posiblemente como graduales, pero en los hechos, es decir, en los análisis concretos, no hay nada de eso. Uno se puede preguntar si la atención y la importancia que los semióticos han atribuido después a la aspectualidad no fue una manera indirecta de aborbar esa gradualidad que el cuadrado semiótico escondía. El mismo Saussure deja entender en una observación sibilina que el término de "diferencia", central en el Curso de lingüística general, se presta al malentendido: "Diferencia, término incómodo, porque eso admite grados"; 41 (ii) el

38 MICHAUX, H. Oeuvres complètes, tomo 2, 2001, p. 373.

39 BAUDELAIRE, Ch. Philibert Rouvière. Oeuvres complètes, 1954, p. 984.

40 La simplicidad es, después de la exhaustividad y de la no-contradicción, el tercer término del "principio de empirismo" de Hjelmslev.

41 Citado por PARRET, H. "Réflexions saussuriennes sur le temps et le moi. Les manuscrits de la Houghton Libary à Harvard", en ARRIVÉ, M. y Cl. NORMAND. Saussure aujourd hui, 1995, p. 46. 
segundo reproche se refiere a la complejidad: desde el punto de vista sistemático la complejidad se plantea dos veces, por el término llamado complejo [S1 + S2] y por el término neutro [no S1 + no S2]. Sin embargo, por lo que conocemos, no ha sido propuesto ningún recorrido que pase ni por el término complejo ni por el término neutro. Los dos reproches están conectados, en la medida en que los términos graduales son complejos, y los términos complejos son graduales.

Para superar esos inconvenientes conviene, entonces, partir de la cantidad, declarándola de entrada y suscribiendo la opinión de Bachelard: “En efecto, debemos comprender desde ahora que hay más y no menos en una organización cuantitativa de lo real que en una descripción cualitativa de la experiencia". ${ }^{42}$

Como nuestro propósito es la conciliación ex abrupto de la cantidad, de la complejidad y de la gradualidad, planteamos, en nombre del derecho a la inciativa, que un continuum finito puede ser analizado, escalonándolo de la manera siguiente:

$$
[\mathrm{S} 1 \ldots \ldots . \mathrm{S} 2 \ldots \ldots \ldots \mathrm{S} 3 \ldots \ldots \ldots . \mathrm{S} 4]
$$

La gradualidad y la cantidad son satisfechas por las premisas conservadas. Según la orientación retenida, habrá "más" en [S2] que en [S1], y recíprocamente: habrá "menos" en [S1] que en [S2]. La complejidad tensiva difiere de la complejidad que emana del cuadrado semiótico, en el sentido de que todos los términos son complejos, aunque no lo son de la misma manera. Partiremos de un ejemplo sencillo, es decir, de una alegoría. Sea el intervalo [grande $\leftarrow \rightarrow$ pequeño]; admitiremos que "grande" contiene una valencia 1 de /grandor/ y una valencia 0 de /pequeñez/, e inversamente para "pequeño"; lo cual nos da el gráfico siguiente:

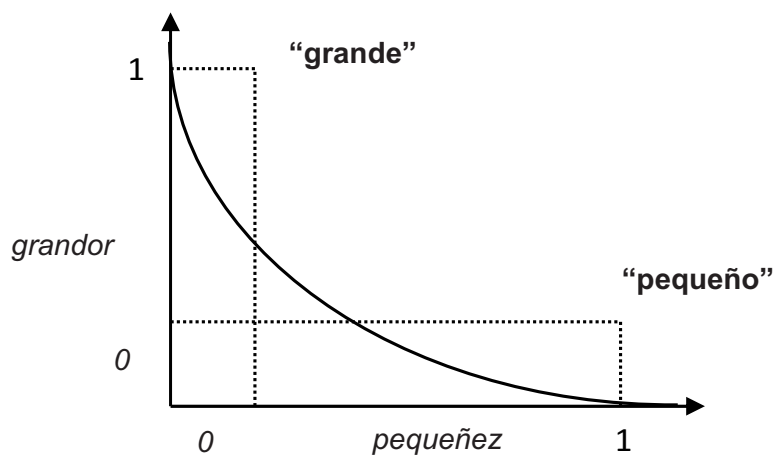

42 BACHELARD, G. Le nouvel esprit scientifique, 1958, p. 66. 
Entre "grande" y "pequeño" se pueden intercalar, especialmente gracias a los adverbios de intensidad, términos intermedios que serán diminutivos para "grande": "es bastante grande", aumentativos para "pequeño": "es bastante pequeño". Las valencias no son enteros sino fracciones mentales de /grandor/ y de /pequeñez/. En tales condiciones, la problemática radica menos en la complejidad que en la divisibilidad o indivisibilidad de las magnitudes manipuladas por los sujetos.

Volvamos ahora a muestra serie de cuatro términos para estudiar el caso en que el intervalo [grande $\leftarrow \rightarrow$ pequeño] sea excedido, si tomamos cada uno de los términos por origen: [pequeño $\rightarrow$ grande $\rightarrow \mathbf{x}$ ] y [grande $\rightarrow$ pequeño $\rightarrow \mathbf{y}$ ], situación que nos da, en ascendencia:
Conviene precisar que no hemos cambiado de problemática, sino solamente de punto de vista, y estirando la metáfora, hemos retrocedido. Este dispositivo sencillo de cuatro términos es evidentemente más rico en posibilidades que el precedente. La relación más interesante sin duda es aquella que acerca, por sus propiedades comunes: de una parte, [S1] y [S4], que solo tienen un punto de contacto: [S2] con [S1] y [S3] con [S4]; de otra parte, [S2] y [S3], que tienen dos puntos de contacto: [S1] y [S3] con [S2], y [S2] y [S4] con [S3].

La terminología adoptada debería manifestar las semejanzas y las desemejanzas manifiestas. Accedemos a dos intervalos corrientes: un intervalo moderado: [S2 $\leftarrow \rightarrow S 3$ ], y un intervalo extremo [S1 $\leftarrow \rightarrow$ S4]. Tenemos que admitir que [S2] y [S3] forman subcon-

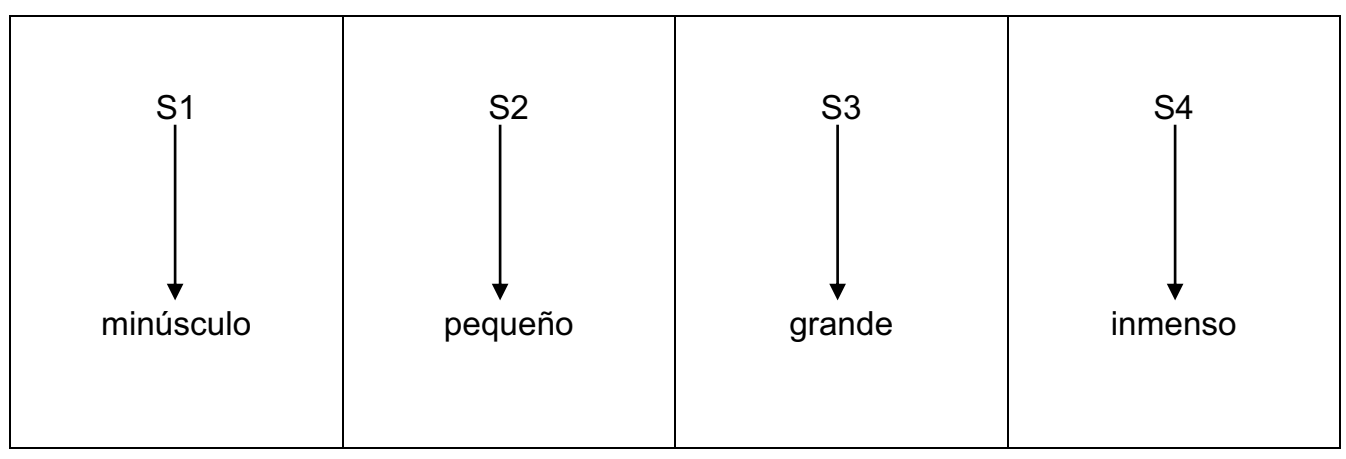


trarios, mientras que [S1] y [S4] constituyen supercontrarios. En segundo lugar, consideramos que [S1] y [S2] habitan la región átona del continuum, y [S3] y [S4] la región tónica. Así: trarios, pero difieren por la tonicidad; [S2] y [S3] se parecen en cuanto subcontrarios, pero se diferencian por la tonicidad. Lo mismo que la rima francesa de los cuartetos exige dos mar-

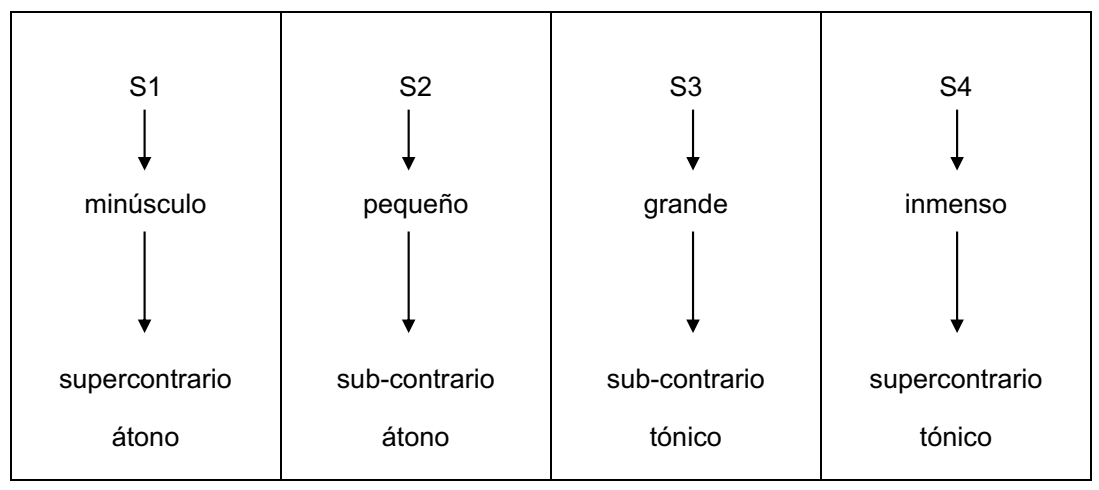

Este dispositivo se parece mucho -y no es por cierto un azar- al cuarteto rimado a la francesa [A-B-B-A]. En efecto, contentarse con señalar, como lo hacía el binarismo sumario de los años sesenta, la oposición [grande vs pequeño] es dejar escapar la vertiente de la semejanza de la relación. La solución greimasiana, que consiste en la "sumación" de un "eje semántico", replantea el cuestionamiento en lugar de resolverlo. La terminología debe integrar -otro aspecto de la complejidad- la semejanza y la desemejanza. [S1] y [S2] son, uno y otro, átonos, pero divergen uno de otro en el grado de contrariedad; [S3] y [S4] son, uno y otro tónicos, pero divergen uno de otro en el grado de contrariedad. [S1] $y$ [S4] se parecen en cuanto supercon- cas: una "riqueza" fonética, a saber, el número de sonidos idénticos, y una marca de género: masculinidad o feminidad, así una característica semiótica demanda, a su vez, dos marcas: una posición en un continuum orientado y un grado.

Este dispositivo de cuatro términos lo designamos con el nombre de matriz, y, bajo beneficio de inventario, le reconocemos tres méritos elementales: (i) independientemente del hecho de que se refiera aquí al espacio, toda matriz, si es satisfactoria, proporciona una profundidad, un espacio de desarrollo, como lo sugiere de manera inigualable el comienzo del texto de Pascal titulado Desproporción del hombre; ${ }^{43}$ (ii) dentro de los límites que implica el ejemplo, elegido por su comodidad, la

43 PASCAL, B. Oeuvres complètes, 1954, pp. 1105-1106. 
definición de cada una de las cuatro magnitudes tiene por definidores el grado de tonicidad en relación con la semejanza y el lugar que ocupa en el continuum orientado en relación con la desemejanza; la definición es ciertamente una división, pero es igualmente una dehiscencia que ajusta una identidad: la relación entre un supercontrario y un subcontrario, ${ }^{44}$ y una alteridad: la relación entre la tonicidad y la atonía; (iii) disponemos de dos intervalos notables: el intervalo mayor [S1 $\leftrightarrow$ S4] y el intervalo menor [S2 $\leftrightarrow$ S3], pero ante toda magnitud semiótica con vocación de convertirse en un punto de vista, podemos proyectar uno sobre otro los dos intervalos disponibles: la proyección de [S1 $\leftarrow \rightarrow$ S4] sobre [S2 $\leftarrow \rightarrow$ S3] hace aparecer un déficit de este último; inversamente, la proyección de [S2 $\leftarrow \rightarrow$ S3] sobre [S1 $\leftrightarrow$ S4] produce, esta vez, la aparición de un exceso:
Nos hallamos en presencia de un dispositivo, de una alternancia que genera por sí misma y no por el hecho del comportamiento equivocado de tal o cual actante, la carencia o el exceso.

La tensividad proporciona a la semántica su dualidad, es decir, su paradigma: distinguimos así una semántica intensiva, que tiene por pivote una medida (mesure), puesto que conocer un afecto consiste ante todo en medirlo, mientras que la semántica extensiva actualiza un número relativo a las magnitudes que moran en el campo de presencia. Este "frente a frente" de una medida afectiva y de un número efectivo es la formulación más abstracta que hemos podido producir. Por lo demás, está de acuerdo con la preocupación por la cantidad que hemos evocado más arriba:

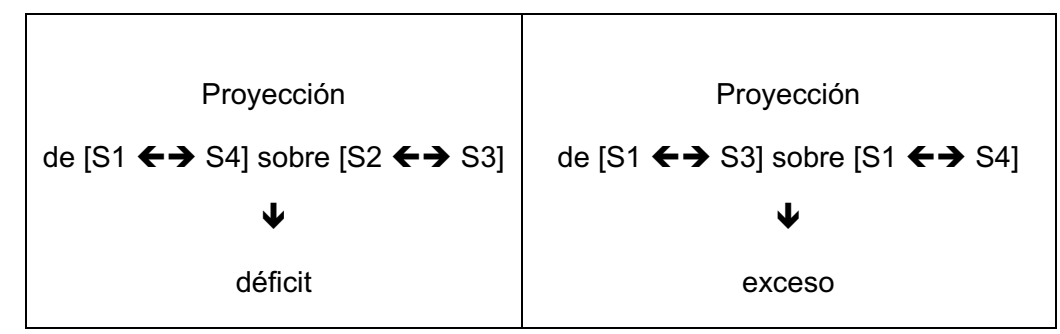

44 Para Wölfflin, la relación entre el arte del Renacimiento y el arte barroco se sitúa dentro de la tonicidad y no entre la tonicidad y la atonía: "El clasicismo busca el grandor, no lo colosal. [...] La iglesia más enorme del clasicismo nos da esa impresión de mesura que la iglesia barroca, incluso de dimensiones reducidas, no nos da ni quiere dárnosla" (Réflexions sur l'histoire de l'art, 1997, p. 68. 


\begin{tabular}{|c|c|c|c|c|}
\hline estructura $\rightarrow$ & super-contrario & sub-contrario & sub-contrario & super-contrario \\
\hline $\begin{array}{l}\text { paradigma } \\
\downarrow\end{array}$ & $\begin{array}{l}\text { átono } \\
\downarrow\end{array}$ & $\begin{array}{l}\text { átono } \\
\downarrow\end{array}$ & $\begin{array}{l}\text { tónico } \\
\downarrow\end{array}$ & $\begin{array}{l}\text { tónico } \\
\downarrow\end{array}$ \\
\hline $\begin{array}{l}\text { semántica } \\
\text { intensiva } \rightarrow\end{array}$ & nulo & débil & fuerte & supremo \\
\hline $\begin{array}{l}\text { semántica } \\
\text { extensiva } \rightarrow\end{array}$ & universal & común & raro & exclusivo \\
\hline
\end{tabular}

La estructura canónica del espacio tensivo, aquella que tiene por resorte una correlación inversa, apela a los cuatro subcontrarios:

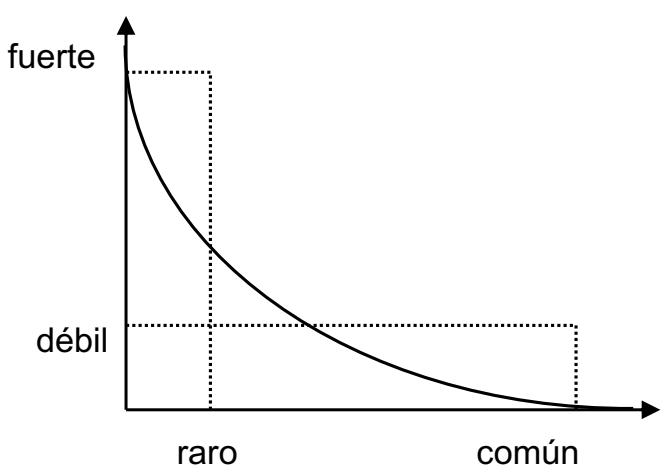

\section{La sintaxis tensiva}

La sintaxis se define en el plano de la expresión por el orden de las posiciones en la cadena; en el plano del contenido, por la naturaleza de las operaciones efectuadas. Como lo indica Semiótica 1: "Otro problema se plantea entonces, el de saber si las relaciones sintácticas son de naturaleza semántica (si son significantes) o si están desprovistas de sentido" ${ }^{45}$ Lo cual equivale, desde nuestro punto de vista, a preguntarse si las operaciones sintácticas son solidarias de la semántica tensiva bajo sus dos modalidades: intensiva y extensiva, o bien si le son extrañas. En nombre de la homogeneidad $^{46}$ y del principio de simplicidad, postularemos que las operacio-

45 GREIMAS, A. J. y J. COURTÉS. Semiótica 1. Diccionario razonado de la teoría del lenguaje, 1982, entrada "Sintaxis, 4".

46 HJELMSLEV, L. Prolegómenos a una teoría del lenguaje. Op. cit., pp. 48-49. 
nes sintácticas son significantes y que, además, son las más simples posibles. ¿Cómo determinarlas? Dando por supuesto que la sintaxis está en concordancia con la semántica tensiva, las operaciones que satisfacen esa demanda son aquellas que le permiten al sujeto desplazarse, recorrer en los dos sentidos los dos paradigmas indicados. Para la semántica intensiva, son operaciones de aumento, literalmente "intensificaciones", y operaciones de disminución. Para la semántica extensiva, son operaciones de selección (tri) y de mezcla (mélange), que recaen sobre el efectivo de una clase.

Debemos mencionar aún dos exigencias más. En primer lugar, tenemos acceso a dos sistemas: el de la intensidad y el de la extensidad. En segundo lugar, el aumento y la disminución, la selección y la mezcla intervienen unas veces como proceso, otras veces como objeto, lo cual da para cada sistema cuatro combinaciones posibles a la espera de una cobertura lexical plausible.

Sintaxis de la intensidad:

\begin{tabular}{|c|c|c|}
\hline Proceso $\rightarrow$ & $\begin{array}{c}\text { Aumento } \\
\downarrow\end{array}$ & $\underset{\downarrow}{\text { Disminución }}$ \\
\hline Aumento $\rightarrow$ & $\begin{array}{c}\text { Aumento de un aumento } \\
\text { redoblar }\end{array}$ & $\begin{array}{l}\text { Aumento de una } \\
\text { disminución } \\
\text { aminorar }\end{array}$ \\
\hline Disminución $\rightarrow$ & $\begin{array}{c}\text { Disminución de un } \\
\text { aumento } \\
\text { atenuar }\end{array}$ & $\begin{array}{l}\text { Disminución de una } \\
\text { disminución } \\
\text { repuntar }\end{array}$ \\
\hline
\end{tabular}

Sintaxis de la extensidad:

\begin{tabular}{|c|c|c|}
\hline Proceso $\rightarrow$ & $\stackrel{\text { Mezcla }}{\Downarrow}$ & $\begin{array}{c}\text { Selección } \\
\Downarrow\end{array}$ \\
\hline Mezcla $\rightarrow$ & $\begin{array}{l}\text { Mezclar mezclas } \\
\text { fusionar }\end{array}$ & $\begin{array}{l}\text { Mezclar una selección } \\
\text { confundir }\end{array}$ \\
\hline Selección $\rightarrow$ & $\begin{array}{c}\text { Seleccionar una mezcla } \\
\text { detallar }\end{array}$ & $\begin{array}{c}\text { Seleccionar una selección } \\
\text { dispersar }\end{array}$ \\
\hline
\end{tabular}


Las denominaciones escritas en cursiva son plausibles, aproximadamente, y no podría ser de otro modo, puesto que si se considera, por ejemplo, que /fusionar/ tiene por definición semiótica "mezclar mezclas", es fácil ver que las denominaciones y las definiciones pertenecen a dominios diferentes: las denominaciones provienen de la lengua corriente, las definiciones pertenecen a un metalenguaje construido a partir de un número lo más restringido posible de restricciones y de valencias. A pesar de esa divergencia, las definiciones de los diccionarios son con frecuencia como un eco atenuado de las categorías tensivas. Así, según el Petit Robert, /fusionar/ remite primero a /fusión/, que se presenta como una "unión íntima resultante de la combinación o de la interpenetración de seres o de cosas". Para/confundir/, el mismo diccionario propone: "Reunir, mezclar para formar un solo todo".

Si tomamos en cuenta la dimensión de la mezcla, /confundir/ aparece en posición de subcontrario, /fusionar/ en posición de supercontrario. Si se acepta que toda fusión implica una profundidad, una dinámica interna, un devenir, diríamos que la mezcla es más favorecida por /fusionar/ que por /confundir/.

En segundo lugar, la sintaxis tensiva está sobredeterminada por lo que hemos llamado modos de eficiencia. El campo de presencia es definido por las magnitudes que acoge. El modo de eficiencia designa la manera como una magnitud se instala en ese campo: según el "llegar a" [arribar], es decir, gradualmente, progresivamente; o bien según el "sobrevenir", es decir, según la sorpresa. El modo de eficiencia, además, perturba el modo de junción, que regula la armonía del campo de presencia: las magnitudes acogidas ¿están en concordancia con el sujeto? En tal caso, hablaremos de implicación; si se instalan contra la volición del sujeto, hablaremos de concesión. Existe, pues, una sintaxis tanto implicativa, o sea "razonable", como concesiva y desconcertante. Para establecerla, acudiremos a los subcontrarios del espacio directivo: [abrir vs cerrar], y los proyectaremos una vez como proceso y otra vez como morfología. Cuatro combinaciones toman cuerpo con esta operación: Dos combinaciones transitivas: Abrir lo cerrado y cerrar lo abierto, y dos combinaciones reflexivas: Abrir lo abierto y cerrar lo cerrado. Desde el punto de vista tensivo, las combinaciones transitivas son implicativas y conformes con la doxa; las combinaciones reflexivas son concesivas y desconcertantes. Tienen por resorte interno la concesión: A pesar de que estoy en presencia de algo ya cerrado, no obstante lo cierro [más]. Lo mismo pasa con lo /abierto/. Desde el punto de vista tensivo igualmente, los sintagmas concesivos son más tónicos que los sintagmas implicativos, lo cual nos conduce a aceptar los sintagmas concesivos como concesivos-super- 
lativos; hiperbólicos en el plano del contenido, esos sintagmas son tendencialmente exclamativos en el plano de la expresión. En el cuadro siguiente hemos puesto en negrita los sintagmas concesivos y en cursiva los implicativos:
De este examen superficial surge el hecho de que la sintaxis es mucho más compleja de lo que se imagina. Nos encontramos en presencia de dos niveles: (i) Un nivel superior, es decir, regente, constituido por la alternancia de la implicación y de la concesión;

\begin{tabular}{|c|c|c|}
\hline $\begin{array}{c}\text { proceso } \\
\downarrow\end{array}$ & $\begin{array}{c}\text { lo abierto } \\
\Downarrow\end{array}$ & $\begin{array}{c}\text { lo cerrado } \\
\downarrow\end{array}$ \\
\hline abrir $\rightarrow$ & abrir lo abierto & abrir lo cerrado \\
\hline cerrar $\rightarrow$ & cerrar lo abierto & cerrar lo cerrado \\
\hline
\end{tabular}

En la medida en que la concesión está del lado del "sobrevenir" permite situar el evento. El evento no está fuera del sistema, no está contra el sistema de las implicaciones vigentes. Sostener eso, como los surrealistas lo han creído de buena fe, es confundir el estatuto y la frecuencia: hijo del "sobrevenir", el evento auténtico es raro, para algunos creyentes único, y debe permanecer como tal; de lo contrario, jreconstituiría muy pronto, a prorrata de sus reiteraciones, la regla que él deniega! (ii) un nivel inferior, regido, constituido por la alternancia de una sintaxis intensiva que opera por aumento y por disminución, y de una sintaxis extensiva, que opera por selección y por mezcla.

\section{Los valores}

Desde el punto de vista semiótico, la problemática del valor se reparte entre dos ubicaciones: el lugar eminente que el Curso de lingüística general le asigna y el lugar que el esquema narrativo, derivado de Propp, le reserva en 
la aproximación greimasiana. Si remitimos esas acepciones a las definiciones que han sido propuestas, tenemos derecho a pensar que nos hallamos en presencia de homónimos, cuya explicitación se formulará tanto como valores-formas, en la aproximación saussuriana, tanto como valores-fines, en la aproximación greimasiana. ${ }^{47}$ Esa dualidad interna del valor es incluso sensible en el sintagma valor del valor, frecuente en la pluma de los semióticos.

El punto de vista tensivo puede contribuir, en alguna medida, a pensar la solución de continuidad entre los valores-formas y los valores-fines. En cierto modo, la problemática es la misma que aquella que hemos encon- trado a propósito de la sintaxis: ¿los valores se encuentran o no bajo la dependencia del sistema de las categorías tensivas? La conciliación de los valores-formas y de los valores-fines resulta fácil en la hipótesis tensiva -tal vez demasiado fácil-. En nuestro propio universo de discurso, cuyo tono lo da Baudelaire en el elogio de Ph. Rouvière, los valores-fines están constituidos por los supercontrarios tónicos: (i) lo /supremo/, que tiene por valencia intensiva el /redoblamiento/ y por valencia extensiva la /selección/; (ii) lo /universal/, que tiene por valencia intensiva el /aminoramiento/ y por valencia extensiva la /dispersión/. Gráficamente:

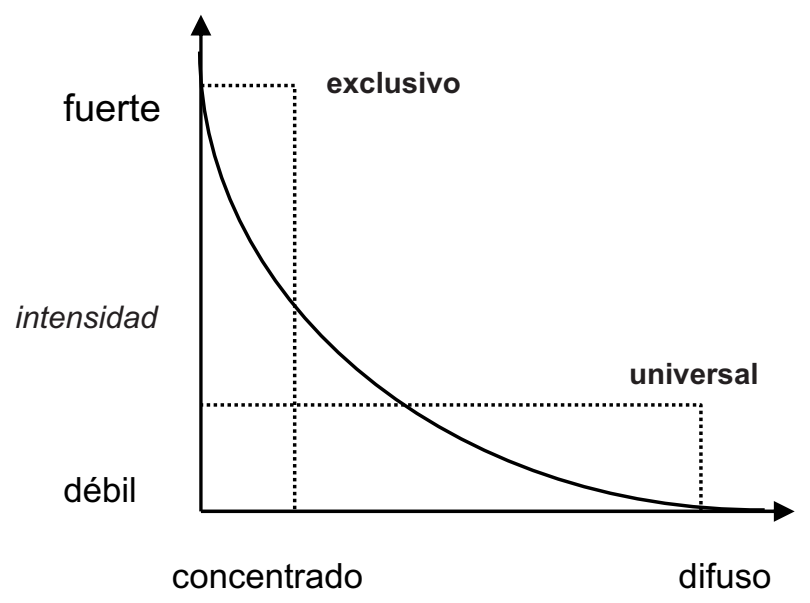

extensidad

47 GREIMAS, A. J. “Un problema de semiótica narrativa: Los objetos de valor”. Del Sentido II. Op. cit., pp. 22-56. 
En cuanto a la terminología, mal inevitable, los valores que afirman lo /exclusivo/ a expensas de lo /univer$\mathrm{sal} /$ son para nosotros valores de absoluto, mientras que los valores que afirman lo /universal/ y desprecian lo /exclusivo/ son valores de universo. De acuerdo con una oposición ya mencionada, el valor de absoluto aprecia una medida alta, que tiene por correlato un número reducido a la unidad, en tanto que el valor de universo se adhiere al grandor de un número de unidades mezquinamente medido. Gráficamente tenemos: res de absoluto se expresará más o menos en estos términos: Considero que los valores de absoluto son superiores porque son fuertes y están concentrados. Su proceder es, pues, implicativo. Pero su estrategia discursiva, en presencia de un contradictor declarado, optará por la concesión: Considero que los valores de absoluto son superiores aunque estén concentrados.

Colocado en la misma situación, el defensor de los valores de universo, se dirá a sí mismo: Considero que los valores de universo son superiores porque son difusos y compartidos. Pero ante un con-

\begin{tabular}{|c|c|c|}
\hline & Valor de absoluto & Valor de universo \\
& lo exclusivo & lo universal \\
\hline intensidad $\rightarrow$ & lo supremo & lo endeble \\
\hline extensidad $\rightarrow$ & la selección & la mezcla \\
\hline referencia $\rightarrow$ & la medida & el número \\
\hline
\end{tabular}

La puesta en discurso de las dinámicas tensivas es particular. Dos casos merecen nuestra atención, según que el enunciador argumente para sí mismo, o bien que se dirija a un enunciatario de opinión diferente. Si reflexiona sin tener que afrontar a un interlocutor-contradictor, el que aboga por valo- tradictor declarado, concederá: Considero que los valores de universo son superiores aunque sean débiles. La concesión es, pues, una elegancia que permite a un enunciador integrar la opinión de un contradictor, y manejar la posibilidad de un acuerdo en el desacuerdo.

Este reparto del espacio tensivo en 
dos regiones simétricas e inversas bajo la doble relación de la intensidad y de la densidad coincide con la descripción de lo sagrado propuesta por Cassirer en el segundo volumen de Filosofía de las formas simbólicas:

La distinción espacial primaria, aquella que no cesa de encontrarse, cada vez más sublimada, en las creaciones más complejas del mito, es la distinción entre dos provincias del ser: una provincia de lo habitual, de lo siempreaccesible, y una región sagrada, que ha sido destacada y separada de aquello que la rodea, que ha sido cercada y que se protege del mundo exterior. ${ }^{48}$

\section{Ilustraciones al paso}

Nos limitaremos a algunas alusiones a situaciones concretas. En razón del lu- gar que atribuimos a la densidad, los dominios en los que interviene una enumeración elevada justifican la alternancia entre valor de absoluto y valor de universo. En primer lugar, la organización social conoce bien esa tensión, que con frecuencia ha tomado la forma de un reparto entre una aristocracia $^{49}$ limitada, exclusiva y de gran brillo y el resto de la población, numerosa y opaca. Bajo el Antiguo Régimen, ¿acaso el aristócrata no se designaba a sí mismo como un "hombre de calidad"? La visión del mundo estaba constituida por el contraste entre una élite, a su vez desigual, es decir, que ejercía sobre sí misma una segunda y severa operación de selección [tri], y una multitud, a la vez fuerte y débil en razón de su número.

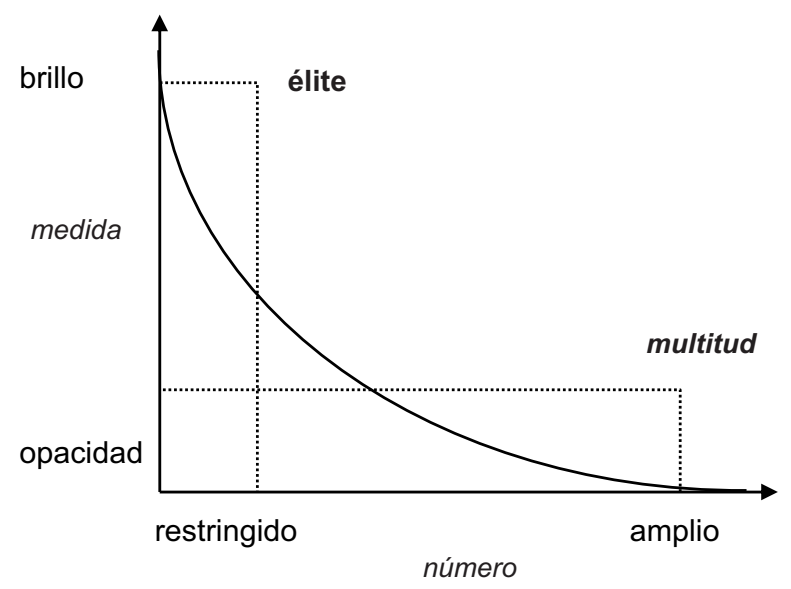

48 CASSIRER, E. Filosofía de las formas simbólicas, tomo 2, 1998, p. 118.

49 Retomamos un ejemplo presentado en FONTANILLE, J. y Cl. ZILBERBERG. Tensión y significación, 2004, pp. 46-48. 
El cambio consiste en un desplazamiento del "acento de sentido", que pasa de la dimensión de la intensidad a la dimensión de la extensidad. Esa dinámica no se agota, ni mucho menos, en el dominio de lo social, porque el mundo animal está, de cara al mundo humano, en la misma posición que la multitud en relación con la élite. En el seno de lo animado se ejerce igualmente una operación de selección asociada a la denegación de valor. Supongamos que esa operación de selección sea suspendida; ¿se extenderá en tal caso a los insectos?

Las figuras amorosas ofrecen la misma alternancia, puesto que tenemos, de un lado, la figura de Tristán, hombre de un solo amor, en concordancia por tanto con el valor de absoluto, y del otro, a Don Juan, que se declara capaz de "amar a toda la tierra":

En fin, no hay nada más dulce que triunfar sobre la resistencia de una bella persona; y en este asunto, yo tengo la ambición de los conquistadores que vuelan perpetuamente de victoria en victoria y no pueden decidirse a poner límite a sus deseos. No hay nada que pueda detener la impetuosidad de mis deseos, me siento como un corazón dispuesto a amar a toda la tierra; y como Alejandro, desearía que hubiera otros mundos para extender a ellos mis conquistas amorosas.

Si la sinceridad de Don Juan fuera cierta, habría llegado a conciliar el valor de absoluto con el valor de uni- verso; pero no es así, porque la problemática de Don Juan no es la -indecible- de la sinceridad. La singularidad de Don Juan reside, a nuestro parecer, en una conjunción de una actualización eufórica y de una realización disfórica. Don Juan es el primero en notar la decadencia próxima, programada, de la pasión amorosa. En relación con el primer punto, declara él mismo: "Las inclinaciones nacientes, después de todo, tienen encantos inexplicables, y todo el placer del amor está en el cambio", pero añade de inmediato: "Mas cuando uno se adueña de él una vez, no hay nada más que decir, ni nada más que desear, todo lo bello de la pasión ha terminado, y nos adormilamos en la tranquilidad de tal amor, a no ser que un nuevo objeto venga a despertar nuestros deseos y a presentar a nuestro corazón los encantos atrayentes de una nueva conquista". Los efectos deletéreos del número, el retorno de la serie, se ponen del lado no de la actualización sino de la realización.

Los efectos de dilución que produce la presencia del número no se limitan al actuar: afectan también, en la pluma de los más grandes escritores, al sentir. En Ilusiones perdidas, Balzac ha captado los efectos tímicos del descubrimiento de la inmensidad del número por Lucien de Rubempré:

Sorprendido ante esa multitud entre la cual se sentía extraño, este hombre de imaginación experimentó una inmensa disminución de sí mismo. Las 
personas que gozan en provincias de alguna consideración y que encuentran allí a cada paso una prueba de su importancia, no se acostumbran a esa pérdida total y súbita de su valor. Ser algo en su país y no ser nada en París son dos estados que requieren transiciones; y aquellos que pasan bruscamente de uno a otro, caen en una especie de aniquilamiento. ${ }^{50}$

Personalmente, no tenemos nada que añadir a ese comentario del autor, que es ya un análisis semiótico del valor en términos de valencias intensivas y extensivas, una elucidación de los méritos de la aspectualización y una confirmación de los efectos, saludables o calamitosos, del tempo sufrido. La posición social de Lucien, que era considerable en Augulema gracias a la protección de Madame de Bargeton, se derrumba en París; Lucien pasa, en ese momento de la novela, de una esfera en la que los valores de absoluto prevalecían sobre los valores de universo, a una esfera donde sucede todo lo contrario.

Para Balzac, un personaje novelesco debe ser, según el "Prólogo" a la Comedia Humana, una "gran imagen del presente", y de hecho, tenemos el derecho de preguntarnos, después de tomar conocimiento de las siguientes líneas de Valéry, si Balzac, el visionario, no ha captado a la perfección la condición del hombre moderno derrotado y desacreditado por el número [o sea, por la multitud]:

Toda novedad se disuelve en las novedades. Toda ilusión de ser original se disipa. El alma se entristece, y se imagina, con un dolor particular, mezclado con una profunda e irónica piedad, a esos millones de seres armados de plumas, a esos innumerables agentes del espíritu, cada uno de los cuales se sintió, en su momento, causa primera, poseedor de una certeza, fuente única e incomparable, y que ahora se encuentra aquí envilecido por el número, perdido entre el pueblo siempre creciente de sus semejantes, él, que no había vivido más que para distinguirse eternamente. ${ }^{51}$

Aquí se impone una puntualización. Daría la impresión de que nuestro análisis, así como la mayor parte de los textos citados, otorgan ventaja a los valores de absoluto, en detrimento de los valores de universo. Si ese fuera el caso, nuestro análisis sería "en algún punto", defectuoso. En principio, si existe un éxtasis de la medida, según la acepción tensiva de este término, hay lugar para prever una efusión del número, que no cede en nada a

50 DE BALZAC, H. Les illusions perdues, 1966, p. 177.

51 VALÉRY, P. "Remerciment à l'Académie Française". Oeuvres, tomo 1, 1968, p. 731. 
la exaltación de la medida. Si los valores del universo resultan altamente decepcionantes, es probablemente porque son examinados y evaluados en función de los valores de absoluto, que los han precedido y que han influido y controlado nuestro universo de discurso. Esta problemática no deja de recordar el tema del "desencanto del mundo", 52 tan caro a M. Weber.

\section{Para concluir}

En un fragmento abrupto de los Cuadernos, Válery anota: "La meta de la obra es la de asombrar al obrero". ${ }^{53}$ Esta máxima toca la profunda paradoja de la reciprocidad de los modos de eficiencia, a saber, el "llegar a", y el "sobrevenir". Existe, ciertamente, una "mira" de la obra, y por vía de consecuencia, una convocación del "llegar a", y no obstante es el "sobrevenir", padre del asombro, el que es determinante. Nos hallamos no tanto en pre- sencia de una espera focalizada cuanto en presencia de una aventura, de una esperanza de cierto tipo por la cual el hacer esperanzador es ejercido menos por un agente que por un paciente confiado y al acecho. Al dejar de definirse por su identidad, por su reproducción, o incluso por su gravedad, el sujeto asombrado accede a su diferencia: "Lo cual hace que el caminante se convierta en camino". ${ }^{54}$

Desde el punto de vista objetal, se trata de que el sujeto refuerce, complete, enriquezca el campo de presencia, como lo sugiere Bröndal, ${ }^{55}$ acogiendo en él magnitudes, por decirlo así, abandonadas. Pero el añadido de una magnitud cualquiera a un conjunto estructurado supone nuevas coordinaciones, un reordenamiento. ${ }^{56}$

En nuestra propuesta, ese reordenamiento es solicitado al espacio tensivo, el cual ajusta razonablemente la complejidad, la gradualidad, y la reciprocidad. Al menos por un tiempo,

52 WEBER, M. Le Savant et le politique, 2003, pp. 83-84.

53 VALÉRY, P. Cahiers, tomo 2, 1973, p. 997.

54 Ibídem, pp. 12-15.

55 Según H. Jorgensen y F. Stjernfelt: "Se puede interpretar este pasaje a partir de estas personificaciones. ¿De quién es la atención en cuestión? ¿Qué es lo que exige una descripción? ¿Quién halla la descripción y propone el objeto? Se puede responder que, en todos los casos, se trata de un proceso detrás del cual vemos al sujeto del discurso intentando ampliar las zonas de validez del discurso, enlazando, de manera relacional y descriptiva, más objetos cada vez al mundo del texto" ("Substance, substrat, structure". Langages 86, junio de 1987, p. 83).

56 Según Hjelmslev: "[La hipótesis] pretende que se definan las magnitudes por las relaciones y no a la inversa" (Essais linguistiques. Op. cit., p. 31). 
porque, como Greimas lo había presentido cuando caracterizaba la semiótica ante todo, como un proyecto, para conservar lo de hoy, hay que cambiar, acoger la novedad que sobreviene sin esperar nada más que una tregua, una benevolencia pasajera.

\section{Bibliografía}

ARENDT, H. Walter Benjamin: 18921940. París: Éditions Allia, 2007.

BACHELARD, Gastón. Poética del espacio. México: Fondo de Cultura Económica, 1997.

—_. Le nouvel esprit scientifique. París, PUF, 1958.

BALZAC, Honoré de. Les illusions perdues. París: Garnier-Flammarion, 1966.

BAUDELAIRE, Charles. "Philibert Rouvière". Oeuvres complètes. París: Gallimard, col. La Pléiade, 1954.

CASSIRER, Ernst. Filosofía de las formas simbólicas. México: Fondo de Cultura Económica, tomo 1 (1998), tomo 2 (1999).

DELEUZE, Gilles. Différence et répétition. París: PUF, 1989.

FOCILLON, Henri. Vie des formes. París: PUF, 1996.

FONTANIER, Pierre. Les figures $d u$ discours. París: Flammarion, 1968.
FONTANILLE, Jacques y ZILBERBERG, Claude. Tensión y significación. Lima: Universidad de Lima, 2004.

GREIMAS, Algirdas Julien. Del sentido II. Madrid: Gredos, 1989.

GREIMAS, Algirdas Julien y COURTÉS, Joseph. Semiótica 1. Diccionario razonado de la teoría del lenguaje. Madrid: Gredos, 1982.

HJELMSLEV, Louis. La categoría de los casos. Madrid: Gredos, 1978.

—. Essais linguistiques. París: Minuit, 1971.

—. Prolegómenos a una teoría del lenguaje. Madrid: Gredos, 1971.

__. El lenguaje. Madrid: Gredos, 1968.

- Principes de grammaire générale. Copenhague: Host \& Son, 1928.

JORGENSEN, Henrik y Frederik STJERNFELT. "Substance, substrat, structure". Langages 86, 1987.

LÉVI-STRAUSS, Claude. El pensamiento salvaje. México: Fondo de Cultura Económica, 1984.

LONGINO. Traité du Sublime. París: Livre de Poche, 1995.

MAUSS, Marcel. Sociología y antropología. Madrid: Tecnos, 1979.

MERLEAU-PONTY, Maurice. La prose $d u$ monde. París: Tel-Gallimard, 1999. 
MICHAUX, Henri. Oeuvres complètes, tomo 2. París: Gallimard, col. La Pléiade, 2001.

PAROUTY-DAVID, Françoise y Claude ZILBERBERG. Sémiotique et esthétique. Limoges: PULIM, 2003.

PARRET, Herman; ARRIVÉ, Michel y Claude NORMAND. Saussure aujourd hui (Colloque de Cerisy). París: Presses de I'Université de París X, 1995.

PASCAL, Blaise. Oeuvres complètes. París: Gallimard, col. La Pléiade, 1954.
STEINER, George. Martin Heidegger. París: Albin Michel, 1981.

VALÉRY, Paul. Cahiers, tomo 2. París: Gallimard, col. La Pléiade, 1973.

-_-. "Remerciment à l'Académie Française". Oeuvres, tomo 1. París: Gallimard, col. La Pléiade, 1968.

WEBER, Max. Le Savant et le politique. París: La Découverte / Poche, 2003.

WÖLFFLIN, Heinrich. Réflexions sur l'histoire de l'art. París: Flammarion, col. Champs, 1997.

ZILBERBERG, Claude. Raison et poétique du sens. París: PUF, 1988. 